\title{
Associação entre intensidade de uso de mídias sociais, credibilidade e decisão de compra
}

\author{
Maria Laura Ferranty MacLennan ${ }^{1}$ \\ Leonardo Fabris Lugoboni ${ }^{2}$ \\ Marcus Vinicius Moreira Zittei ${ }^{3}$ \\ Ricardo Yassuo Tabata $^{4}$ \\ Hamilton Luiz Correa ${ }^{5}$
}

\begin{abstract}
RESUMO
O objetivo desta pesquisa é analisar o uso de mídias sociais, credibilidade das informações on-line com as decisões de compra de consumidores. Com base em referencial teórico sobre redes sociais, mídias sociais e comportamento de compra on-line, realizou-se esta pesquisa. Os dados foram levantados por meio de survey eletrônico e analisados com o uso de análise fatorial e regressão linear múltipla. Os resultados indicam a associação entre a decisão de compra do cliente e a intensidade de acesso na internet. Também se relacionam a decisão de compra e a importância das informações consultadas na internet, de modo que, quanto maior o tempo e a exposição a conteúdos on-line, maior a influência da exposição no ambiente on-line nas decisões de compra dos usuários. Diferentemente de estudos anteriores, não se observa significância entre as variáveis gênero e idade dos respondentes nas decisões de compra da amostra investigada.
\end{abstract}

Palavras-chave: Mídias sociais. Decisão de compra. Internet. Comportamento de compra.

\section{INTRODUÇÃO}

Em tempos de internet, a comunicação entre pessoas desconhecidas no ambiente on-line ganha destaque. Nesse contexto, a importância de recomendações e de validação de produtos, serviços e marcas na internet é crescente. De acordo com a pesquisa da Nielsen Global Survey of Trust in Advertising (2013), as opiniões dos consumidores postadas on-line são a terceira fonte de informação mais confiável na comunicação e propaganda entre empresas e consumidores. Segundo a referida pesquisa, essas opiniões são consideradas mais confiáveis do que propagandas na televisão, rádio e em revistas. Elas perdem em confiabilidade apenas para recomendações provenientes de pessoas conhecidas e web sites com marcas reconhecidas (NIELSEN GLOBAL SURVEY OF TRUST IN ADVERTISING, 2013). A confiabilidade das opiniões postadas on-line cresceu sete pontos percentuais em relação ao mesmo levantamento conduzido em 2007, o que indica tendência de fortalecimento da importância de comentários em grupos de discussão, opiniões postadas em web sites, mídias sociais, comunidades e outros canais no meio virtual.

Segundo Joines, Scherer e Scheufele (2003), o uso da internet voltado ao consumo está se tornando a principal razão de acesso das pessoas à rede. Este se dá por diversas razões, tanto no uso com a finalidade de realizar compras on-line, quanto para a busca de informações a respeito de produtos e serviços. Seguramente

\footnotetext{
1Doutoranda em Administração (FEA/USP). Mestre em Administração. Professora do Centro Universitário Senac - ferranty@hotmail.com ${ }^{2}$ Doutorando em Administração (FEA/USP). Mestre em Administração. Professor da FECAP - leo_fabris@hotmail.com

${ }^{3}$ Doutorando em Ciências Contábeis e Administração (FURB). Mestre em Ciências Contábeis. Professor da FECAP - marcuszittei@zittei.com.br

${ }^{4}$ Especialista em Controladoria. Estudante da FECAP/USP - tabata.ricardo@gmail.com
}

${ }^{5}$ Doutor em Administração. Professor FEA/USP - hamilco@usp.br 
a internet influencia no comportamento do consumidor atual (NAGAKAWA; GOUVÊA; OLIVEIRA, 2013); por tal razão, as empresas têm considerado a internet como mais um canal de marketing (CARVALHO, 2013). Todavia, a comunicação no ambiente virtual possui suas particularidades, pois, além do conteúdo disponível, importa igualmente o volume, origem e intensidade expressa nos posts on-line (GARTON; HAYTHORNTHWAITE; WELLMAN, 1997). Nesse sentido, identifica-se uma lacuna na literatura no que concerne à compreensão da influência das opiniões e informações advindas das redes sociais e do ambiente virtual nas orientações dos consumidores na aquisição de produtos e serviços.

\subsection{Objetivo geral}

Conforme Claro, Souza e Mena (2013), a rede social na internet pode ser definida como interação social mediada pelo computador. Com a disseminação e popularização da internet, as redes sociais registram amplo crescimento no Brasil (MANTOVANI; SANTOS JUNIOR, 2013). Essas redes não somente podem influenciar seus próprios participantes, como também impactar decisões de compras e de consumo nos ambientes on-line e off-line. Assim, o presente artigo analisa a influência das opiniões postadas em redes sociais na aquisição de produtos por consumidores.

\subsection{Objetivos específicos}

Os objetivos específicos da pesquisa são: (i) verificar se a intensidade de acesso a mídias sociais (tempo on-line) influencia na decisão de compra dos consumidores e (ii) constatar se há relação entre a credibilidade e a importância das opiniões dadas na internet nas decisões de compra dos consumidores.

\section{MEIO VIRTUAL E COMUNICAÇÃO EMPRESARIAL}

O meio virtual pode ser usado pelas empresas de forma ativa como canal de comunicação com seu público, ao servir como ferramenta de informação para o mercado. Notícias relativas ao que ocorre em uma empresa, como alterações societárias, resultados financeiros e lançamento de novos produtos e serviços, podem ser veiculadas on-line (VAN RULER, 2004). A comunicação entre as pessoas e as empresas no ambiente virtual apresenta caráter multidirecional, em que os geradores de conteúdo podem estar dentro ou fora da organização (TERRA, 2011). Tentar controlar o envio de informações emitidas por pessoas ou organismos situados fora da organização constituirá um fracasso, pois a emissão de informação de maneira informal hoje se apresenta como uma realidade incontrolável, principalmente quando avaliamos os fenômenos da internet e da disseminação dos smartphones (WOERKUM; AARTS, 2008).

Nesse contexto, Castells (2003, p. 8) afirma que a "Internet é um meio de comunicação que permite, pela primeira vez, a comunicação entre múltiplos indivíduos, em um momento específico e em escala global". Logo, essa rede constitui uma transformação nas mais diversas relações sociais pela utilização de um novo meio de comunicação. A internet possibilitou a expressão e sociabilização por intermédio de computadores, permitindo que as pessoas interajam e se comuniquem com outras pessoas, conhecidas ou não, de modo informal (TOMAÉL et al., 2001).

A partir da ideia de que a internet é um sistema tecnológico socialmente produzido (CASTELLS, 2003), surge a noção de cultura da internet. Nessa, a cultura dos produtores da internet molda o meio, que se apresenta em quatro camadas da internet inter-relacionadas, produzindo uma cultura essencialmente da rede. A primeira camada, citada pelo autor, é a chamada de tecnoelites. Os participantes da tecnoelite seguem a tradição acadêmica, ao zelar pela excelência científica, com práticas como o exame dos pares e abertura com relação a todos os achados de pesquisa, com o devido crédito aos autores de cada descoberta. A segunda camada é apontada como cultura Hacker. Nela, os Hackers são os responsáveis pela transição de um ambiente de inovação acadêmica, institucionalmente construído, para o surgimento de redes autogeridas que escapam do controle organizacional. Já as comunidades virtuais formam a terceira camada. Tais comunidades seriam fontes de valores que moldam novo comportamento e organização social. A quarta camada é formada pelas empresas, que possuem um importante papel no funcionamento da internet. Portanto, as empresas podem, por exemplo, atuar de forma ativa, com a possibilidade de gerar informações de rápida disseminação na internet, como por exemplo, os chamados virais (CARVALHO, 2013; VAN DER HEIJDEN; VERHAGEN; CREEMERS, 2003).

Algumas empresas também têm utilizado as redes sociais como meio de construção da sua imagem e reputação, além de canal para divulgação de seus produtos, marcas e serviços (CRUZ et al., 2012). 0 uso 
de redes sociais para veiculação de informações sobre produtos, serviços e marcas é chamado de mídia social, seja por empresas, seja por indivíduos. Terra (2011) esclarece que a web 2.0 permite, por meio das ferramentas chamadas mídias sociais, que seus usuários participem, compartilhem, exponham, opinem e colaborem conteúdos com outros internautas da rede.

Diante desse novo cenário, grandes empresas passam a considerar as mídias sociais em sua estratégia de comunicação com o mercado. A Gerdau, por exemplo, iniciou processo de monitoramento dos conteúdos com menções à empresa na internet (CARDOSO, 2013). Tal ação foi tomada com a finalidade de diagnosticar sua presença digital e desenvolver uma estratégia de atuação no ambiente virtual. A empresa planejou a sua atuação em ambientes virtuais, como Facebook, Twitter, LinkedIn e You Tube. A GE também é outro exemplo de empresa com atuação nas mídias sociais; lançou, em 2012, sua página no Facebook e no Twitter a fim de "humanizar a empresa" sob a perspectiva do consumidor (MENEZES, 2013). As empresas comumente registram seus próprios domínios, em iniciativa voltada à personalização da sua presença na internet e ao ganho de credibilidade na rede (MOTTA, 2013). Contudo, a atenção às interações on-line e às mídias sociais ainda é considerada comportamento novo nas empresas. Conforme Nassar (2013), apenas 39\% dos profissionais de comunicação entendem as mídias sociais e virtuais como parte da responsabilidade do escopo do profissional de comunicação.

Outro fenômeno também observado na internet é o surgimento de comunidades virtuais. Tais comunidades emergem espontaneamente a partir da reunião de pessoas em grupos de discussão sobre experiências pessoais, esportes, passatempos, política, religião ou, até mesmo, a fim de desenvolver relacionamentos afetivos (RIDINGS; GEFEN; ARINZE, 2002). Os membros das referidas comunidades são comumente pessoas desconhecidas entre si. As comunidades permitem a participação democrática entre seus membros, além da formação de amizades e a rápida disseminação de informações, recomendações e opiniões em ambiente cooperativo (MANTOVANI; SANTOS JUNIOR, 2013; TOTOLI; ROSSI, 2012). Assim sendo, sua grande vantagem é a oportunidade de criar uma arena de livre expressão voltada à prática e à troca de experiências, ao permitir rápido acesso à informação (CASTELLS, 2003).

As mídias sociais, redes sociais e as comunidades virtuais possibilitam a expressão individual pela criação de perfis públicos, redes de contato e a interação entre as pessoas, ao consentir publicações de opiniões, experiências e impressões. Tais meios de expressão individual corroboram como ato de compartilhar e construir conteúdo coletivamente (MANTOVANI; SANTOS JUNIOR, 2013). Diversas formas de laços sociais, como redes sociais, comunidades virtuais ou informações disponíveis em sites oficiais de empresas, caracterizam o ambiente virtual, ao refletir interações em diversos espaços e sistemas (RECUERO, 2009). Anderson (2009) lembra que cada vez se observam mais amadores criando e contribuindo gratuitamente com "n" motivações, como desenvolvimento pessoal e produção de conhecimento compartilhado.

Vaz (2012) salienta que as mídias sociais não são produtos diretos da web 2.0, e sim apenas ferramentas. De acordo com o autor, as redes sociais permitiram que as pessoas se tornassem mais coletivas, possibilitando que esse anseio da humanidade fosse libertado. Segundo Vaz (2012), as mídias sociais trazem à tona um novo modelo econômico chamado de produção social. Nesse modelo, a produção ocorre de forma colaborativa, em que as pessoas se auto-organizam em grupos autogeridos. As mídias sociais apresentam uma configuração que favorece a discussão bidirecional, impedindo a moderação e a censura. Seus personagens centrais são os usuários e não as empresas ou marcas (TERRA, 2011). A rede apresenta duas principais características: permitir a comunicação livre e horizontal, e possibilitar que cada indivíduo avance rumo à sua própria destinação na net (formação autônoma das redes) (CASTELLS, 2003). Mantovani e Santos Junior (2013) indicam alguns exemplos de redes sociais na internet, como Facebook, Orkut, Twitter e LinkedIn, arenas onde as pessoas podem buscar informações, além de ter a oportunidade de expressar seus próprios sentimentos a respeito de produtos, serviços e marcas.

Por causa da crescente importância das redes sociais e mídias sociais na interação entre empresas e consumidores, convém conceituá-las e diferenciá-las. De acordo com Totoli e Rossi (2012), mídia social é um meio aberto para comunicação interativa que foi desenvolvido por indivíduos. Nela, a geração e a troca de conteúdo por um grupo de pessoas ocorrem com base em suas conexões pela internet. A mídia social permite que consumidores tornem-se igualmente produtores de conteúdos (TERRA, 2011), por conta do seu alto nível de interatividade. A rede social, por sua vez, é formada por pessoas que compartilham um interesse, como gosto por tênis de mesa, por exemplo. Rede social é uma rede de pessoas com algo em comum, comunidades não limitadas ao Facebook ou ao Twitter (TOTOLI; ROSSI, 2012). Pode-se dizer que o conjunto de pessoas que apreciam música clássica forma uma rede social, mas não significa que elas estejam presentes somente no Facebook, esta sim uma mídia social.

Em virtude da tamanha diversidade, os usuários da internet passam a desenvolver não somente a habilidade de encontrar as informações pertinentes aos seus anseios pessoais, mas também de compartilhá- 
las de forma síncrona e assíncrona (PATRICK; DOTSIKA, 2007). Kotler, Kartajaya e Setiawan (2010) propõem que existe a necessidade de as pessoas darem certo firmamento a figuras menos conhecidas, pois enxergam como a si próprios. Faz-se vital constatar a ideia de empoderamento do consumidor. Torna-se necessário compreender que atualmente a missão da empresa ou marca é de responsabilidade também dos consumidores, já que estes se sentem "donos" dessas marcas quando desenvolvem um vínculo afetivo. Às empresas resta o desafio de se adequar a essa nova realidade em que há perda de controle sobre a comunicação da marca e a missão da empresa; uma vez que, criado esse vínculo afetivo com os clientes, a comunicação é transferida para a missão desses consumidores "fãs".

De acordo com Terra (2011), cada indivíduo é um canal de mídia: um produtor, criador, compositor, etc., de onde se formou o termo usuário-mídia, possibilitando a tais pessoas utilizar essas mídias digitais como instrumentos de divulgação, exposição e expressão pessoal. Surgem então novas formas de sociabilidade fruto da consolidação da internet, em especial, realizando um contraponto entre as comunidades virtuais e o individualismo em rede, como possibilidades de transformações das relações sociais entre indivíduos e empresas, por meio de uma nova forma de interação. Castells (2003) entende que os indivíduos estão de fato reconstruindo o padrão da interação social, com a ajuda de novos recursos tecnológicos a fim de criar uma nova forma de sociedade: a sociedade em rede.

\section{CONSUMO E REDES SOCIAIS}

O comportamento do consumidor e o consumo são temas amplamente abordados na literatura. 0 consumo, especificamente, está relacionado aos valores da sociedade e suas atitudes. 0 indivíduo ao consumir incorpora valores associados ao objeto consumido, que podem ser representados por imagens e símbolos, e dão origem a uma série de significados (CAMPBELL, 2001). Logo, o consumo é uma forma de diferenciação individual que pode gerar sensação de pertencimento a grupos de referência. Nos grupos de referência, valores presumidos são usados pelo consumidor como base para o seu comportamento de compra (CERETTA; FROEMMING, 2011).

O comportamento de compra pode ser influenciado por diversos tipos de valores: pessoal, central e social (ROKEACH, 1973). Os valores básicos são definidos como categorias de orientação nas necessidades humanas. Tais valores podem ser subdivididos nas funções psicossociais: pessoal (experimentação e realização), central (existência e suprapessoal) e social (interacional e normativo). 0 fator social trata sobre como a família e os grupos de referência exercem influência nas decisões de consumo das pessoas. 0 grupo de referência pode ser formado por pessoas conhecidas ou desconhecidas. Nele são considerados as pessoas ou grupo que influenciam de modo relevante o comportamento de compra individual (BEARDEN; ETZEL, 1982).

A internet permite que consumidores e empresas comprem produtos e serviços a partir de seus lares ou escritórios localizados em diversos lugares do mundo. Para que a compra ocorra, um dos estágios do processo de decisão de compra é a busca de informações. Solomon (2002) alerta que existem duas características importantes para a fonte: (i) a credibilidade, que consiste no conhecimento e na confiabilidade que a fonte disponibiliza; (ii) a atratividade, que se refere ao "valor social percebido da fonte", podendo proceder de atributos como aparência física, personalidade, status social ou sua semelhança com o receptor. Opiniões e experiências são compartilhadas na rede virtual e permitem o acesso a informações oficiais da empresa e às impressões de usuários em geral. Na web, podem ser superadas barreiras relacionadas com a distância geográfica, sexo, cor e posição social entre os indivíduos ali envolvidos (GARTON; HAYTHORNTHWAITE; WELLMAN, 1997). 0 desenvolvimento tecnológico permite flexibilidade na troca de informações e formação de laços sociais, à medida que o relacionamento é possível independentemente da distância física entre os indivíduos. A interatividade é uma característica da internet que consente ao consumidor a procura por informações do mercado de modo ativo, distinta dos padrões de comunicação tradicional em que a propaganda busca alcançar os diversos públicos de interesse (JOINES; SCHERER; SCHEUFELE, 2003).

Blackwell, Miniard e Engel (2001) analisam o comércio eletrônico sob a ótica do consumidor. Nessa análise, os autores elencam benefícios e inibidores às compras feitas no meio virtual. 0 modelo proposto por Blackwell, Miniard e Engel (2001) pode auxiliar no entendimento da interação social ocorrida na internet. 0 modelo é composto por quatro etapas apontadas na Figura 1. 


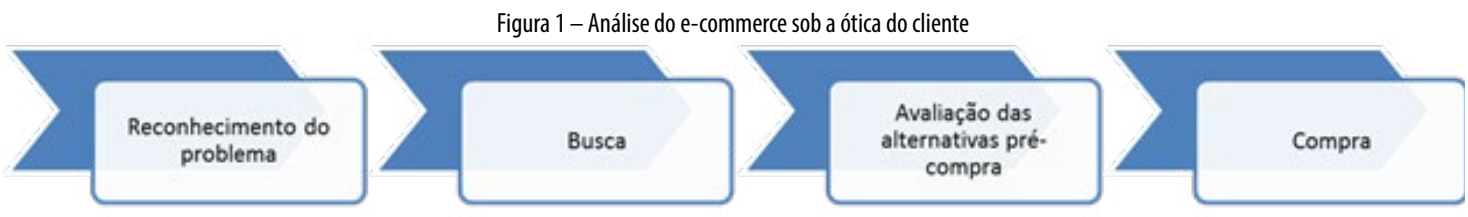

Fonte: Adaptado de Blackwell, Miniard e Engel (2001)

No modelo apresentado, a primeira etapa envolve o reconhecimento do problema. Nela, o consumidor pode compreender quais itens do processo de compra podem ser mais bem resolvidos pela internet (BLACKWELL; MINIARD; ENGEL, 2001). 0 comprador avalia questões como a distância do ponto de venda, as suas limitações no horário de compras e a dificuldade de encontrar produtos com alguma particularidade, como tamanhos especiais, sabores exóticos ou itens já esgotados. Nesta etapa, igualmente são avaliadas as limitações do ambiente on-line, como, por exemplo, a impossibilidade de contato sensorial com o produto (dificuldade de toque ou experimentação) (BLACKWELL; MINIARD; ENGEL, 2001).

A segunda etapa envolve o processo de busca. Nesta etapa, o cliente utiliza a internet como facilitador na obtenção de informações importantes para a decisão de compra (BLACKWELL; MINIARD; ENGEL, 2001). Nesta fase, observam-se alguns benefícios no ambiente virtual, como acesso à ampla variedade de fontes de informações, transcendendo inclusive limites geográficos. Existe, do mesmo modo, a possibilidade de identificar marcas, pontos de venda e informações a propósito do produto de interesse, mesmo que sejam comercializados em outras regiões ou países, o que torna a possibilidade de busca global. Segundo Tomaél et al. (2001), a internet ampliou as fontes de informação disponíveis, pois, além das tradicionais, podem-se acessar bibliotecas digitais, repositórios, sites de busca (search engines), comunidades virtuais, mapas online e grupos de discussão. As fontes de informação apresentam-se em formato multimídia (texto, imagem, vídeo e som).

Contudo, vale alertar que a disponibilidade e a fartura de informações podem também resultar em dispersão do consumidor no processo de busca. Isso principalmente quando o cliente não sabe claramente o que procura na internet. Van der Heijden, Verhagen e Creemers (2003) incluem uma nova variável importante na busca de informações nas mídias sociais: a consulta a informações postadas em comunidades, grupos de discussão e sites especializados em acolher reclamações e insatisfações no processo pós-vendas. Conforme entendimento de Tomaél et al. (2001), as mídias sociais podem ser consideradas ferramentas de armazenamento, recuperação e disseminação de informações. Porém, em tal teia comunicacional é difícil delimitar a confiabilidade das informações coletadas.

A avaliação das alternativas pré-compra representa a terceira etapa apontada no modelo. Compreende a possibilidade de comparar com as ofertas identificadas na busca no ambiente virtual com itens ofertados pela concorrência (BLACKWELL; MINIARD; ENGEL, 2001). No meio virtual, os clientes podem comparar preços e produtos de diferentes varejistas. Tal comparação pode ser orientada a preço ou às características e atributos do produto. Todavia, apesar de o ambiente virtual possibilitar comparação de amplo rol de características, nem todos os atributos são verificáveis por meio da pesquisa virtual, uma limitação do ambiente em questão (BLACKWELL; MINIARD; ENGEL, 2001). Ainda, em virtude da informalidade, a maioria dos conteúdos não detalha dados técnicos, como autoria, corpo editorial ou vínculo institucional. A informalidade da internet estimula a livre comunicação; entretanto, também incrementa a quantidade de fontes voláteis na rede (TOMAÉL et al., 2001).

Finalmente, Blackwell, Miniard e Engel (2001) avaliam a compra on-line e apresentam as suas vantagens e desvantagens. Os autores verificam que as compras pela internet proporcionam benefícios quando o cliente não pode se dirigir à loja, se estiver familiarizado com o produto pedido, se não necessitar disponibilizar do produto imediatamente e se encomendar o bem por telefone for difícil ou inconveniente. As compras pela internet apresentam dificuldades muitas vezes não observadas no ambiente físico. Alguns exemplos são a cobrança de fretes, a necessidade de embalagens especiais e a dependência de serviços de entrega.

Ainda vale abordar o problema da confiança no comércio eletrônico. Tal aspecto pode ser considerado crítico, uma vez que importa para a decisão de compra a confiança do usuário em relação aos aspectos de credibilidade do meio de compra e do site de comércio eletrônico (FERNANDES; RAMOS, 2012). Garbarino e Strahilevitz (2004) elencam os cinco principais riscos identificados nas compras on-line: uso indevido do cartão de crédito, existência de sites e lojas fraudulentos, perda de privacidade, problemas associados ao processo de entrega do produto e falhas no produto. No entanto, apesar desses riscos, os autores evidenciam que a recomendação de uma loja por um amigo ou conhecido diminui fortemente a percepção de risco no ambiente virtual. Outro risco já abordado trata da confiabilidade das informações (TOMAÉL et al., 2001). 
Sobre tal aspecto cabe ao usuário verificar a procedência e consistência das opiniões postadas, além da reputação da fonte.

\section{DEFINIÇÃO DE HIPÓTESES}

0 uso de redes sociais não se restringe à relação das pessoas com produtos, marcas ou empresas no ambiente virtual. Do mesmo modo que as redes sociais ajudam a organizar ações fora do ambiente virtual para fins políticos, elas podem influenciar decisões de compra de produtos e serviços no meio físico (MARTELETO, 2001).

As decisões de compra dos usuários podem ser influenciadas pela intensidade de uso de mídias sociais pelo consumidor. Conforme estudo de Ellison, Steinfield e Lampe (2007), a intensidade de uso de redes sociais, como o Facebook, acarreta uma série de efeitos nos usuários. Alguns exemplos podem ser citados, como efeito de relacionamentos mais intensos em redes sociais. Esses possibilitam maior número de interações entre os participantes da rede, intensificação de relacionamentos, ao fortalecer os vínculos entre os participantes, e a diminuição de barreiras de comunicação entre os seus usuários. Logo, quanto maior a intensidade da visualização de informações ou opiniões on-line, maior a sua influência nas decisões de compra. Assim sendo, propõe-se a primeira hipótese:

H1: Quanto maior a intensidade do acesso às mídias sociais, maior a sua influência nas decisões de compra dos usuários.

Recuero (2009) lembra que as interações na internet mantêm os rastros sociais dos indivíduos, que permanecem ali. Um comentário em um blog, por exemplo, permanece acessível até que alguém o apague ou o blog saia do ar. Assim ocorre com a maior parte das interações mediadas pelo computador, seja ela entre indivíduos, seja entre consumidores e empresas. Tais interações são, de certo modo, propensas a permanecer no ciberespaço, permitindo ao pesquisador a percepção das trocas sociais. Vale lembrar que, ainda que o registro de informações aconteça de modo perene, ele ocorre muitas vezes de maneira desestruturada (MANTOVANI; SANTOS JUNIOR, 2013). Cabe ao usuário acessar e validar as informações disponíveis na internet que lhe são pertinentes e formar suas opiniões de acordo. Assim, quanto maior a crença dos usuários na validade e importância das opiniões expostas nas mídias sociais, maior a sua propensão à compra. Dessa maneira, formula-se a segunda hipótese:

H2: Quanto maior a importância atribuída aos conteúdos acessados on-line, maior a sua influência nas decisões de compra dos usuários.

\section{METODOLOGIA}

A presente pesquisa, de abordagem quantitativa, coletou respostas de 206 usuários de redes sociais. Com o objetivo de verificar se há influência das informações obtidas no ambiente on-line na decisão de compra de consumidores, foi realizada uma survey com amostra não probabilística (COOPER; SCHINDLER, 2006). A pesquisa pode ser classificada como de natureza exploratória, pois há pouca familiaridade e conhecimento sobre as mídias sociais e suas dimensões (MALHORTRA, 2001). Optou-se pelo estudo exploratório, buscou a literatura que relaciona as variáveis - comunicação na internet entre diferentes públicos, mídias sociais, intensidade de acesso on-line e credibilidade das informações - porém, pouca literatura foi encontrada. Assim, por não haver corpo teórico robusto, não é possível realizar estudo de natureza descritiva ou causal.

Os dados foram coletados por meio de questionário eletrônico na internet (WRIGHT; SCHWAGER, 2008). 0 instrumento ficou acessível em abril de 2012, após uma rodada de pré-teste ocorrida em março do mesmo ano com um professor da área. Os respondentes foram convidados a participar da pesquisa por meio de convite via e-mail, em que puderam acessar um link que os direcionou para a página criada especificamente para o levantamento dos dados. 0 e-mail foi encaminhado para os contatos dos autores, o que gerou uma amostra não probabilística. 0 instrumento incluiu questões sobre as seguintes características sociodemográficas do respondente: gênero, idade, grau de instrução, local e tipo de tecnologia usada para acessar a internet. 0 instrumento de pesquisa utilizou a escala Likert, que é recomendada para a coleta de dados sobre atitudes, crenças e valores, entre outros construtos latentes, em escalas de investigação com diversos itens (WONG; RINDFLEISCH; BURROUGHS, 2003). Para a coleta, utilizou-se a escala Likert de 1 a 5 pontos. Os dados foram analisados por meio do software Statistical Package for the Social Sciences (SPSS), que possibilitou a análise das estatísticas descritivas, bem como análise multivariada (neste artigo, regressão linear múltipla). 
Vale lembrar que o escopo delimitado na pesquisa aborda de modo exploratório as redes virtuais, informais e formais entre consumidores e empresas, com base no que foi expresso pelos usuários da internet (amostra selecionada). Este trabalho não almeja estudar a comunicação no ambiente virtual do ponto de vista das empresas. Também não se investiga a influência da comunicação on-line na reputação de personalidades públicas, artistas, países ou políticos, por exemplo.

\subsection{Definição das variáveis de pesquisa}

A variável dependente no estudo é a decisão de compra. A referida variável tem em vista medir o resultado das opiniões coletadas on-line na decisão de compra do respondente. Ela foi calculada por meio das seguintes questões: (i) Você já comprou algo, baseado nas opiniões da sua rede social? e (ii) Você já deixou de comprar algo, baseado nas opiniões da sua rede social?. O Alpha de Cronbach é de 0,734 e pode ser considerado bom ou satisfatório (HAIR et al., 2009).

A variável independente, intensidade no acesso às mídias on-line, foi medida pelas seguintes questões: (1) Qual o tempo médio que você gasta diariamente na internet? (não considere o tempo gasto no trabalho/ emprego). (2) Qual o tempo médio que você gasta diariamente em mídias sociais? A intensidade foi medida com escala Likert de 1 a 5 pontos, e 1 ponto significa até 2 horas, 2 pontos são de 3 a 5 horas, 3 pontos são de 6 a 8 horas, 4 pontos são de 9 a 11 horas e 5 pontos foram atribuídos para usuários com mais de 11 horas. 0 Alpha de Cronbach é de 0,676, considerado moderado (HAIR et al., 2009).

Para medir a importância atribuída às opiniões expostas nas mídias sociais (variável independente), utilizou-se escala de Likert de 1 a 5 pontos. Nela, 1 representa sem influência e 5 muita influência. As questões são estas: (3) Uma opinião positiva na sua mídia social tem maior relevância na sua intenção de compra? (4) Quando você precisa comprar algo, você se lembra de qual era a opinião do produto/marca/ empresa de dentro da sua mídia social? (5) Quando você precisa comprar algo, você se lembra de quem deu uma opinião do produto/marca/empresa de dentro da sua mídia social? O Alpha de Cronbach é de 0,745, valor avaliado como bom (HAIR et al., 2009).

Algumas variáveis foram controladas no estudo. Utilizou-se a idade dos participantes para separar os indivíduos considerados jovens (adultos com até 28 anos). Isso porque tal separação compreende indivíduos habituados à internet e aos computadores. Eles já cresceram em ambiente no qual o compartilhamento de informações e o contato com indivíduos de modo virtual são recorrentes dentro e fora das empresas (SMOLA; SUTTON, 2002). Para tal foi criada uma dummy, em que 1 representa indivíduos com até 28 anos e 0 são os adultos com idade igual ou superior a 29 anos.

Outra variável controlada foi o gênero dos participantes. Novamente se utilizou uma variável dummy que codifica 0 como sexo masculino e 1 como sexo feminino. Segundo Akhter (2003), variáveis como gênero e idade influenciam no comportamento on-line das pessoas, o que justifica seu controle. Garbarino e Strahilevitz (2004) também observaram a influência do gênero no comportamento do consumidor na internet. Eles salientam que uma recomendação proveniente de uma fonte conhecida reduz o risco percebido por mulheres em uma proporção maior do que aqueles reportados por homens. Por isso, o gênero do respondente foi controlado no estudo (ABREU et al., 2010; AKHTER, 2003; GARBARINO; STRAHILEVITZ, 2004).

\section{RESULTADOS}

Para a análise dos resultados da amostra, inicialmente utilizou-se estatística descritiva. A amostra pesquisada é constituída de 206 respondentes, em que 50\% dos respondentes são homens e 50\% são mulheres. Dentre os respondentes, 61\% possuem idade entre 18 e 28 anos. Observa-se na amostra bom nível de escolaridade, pois $83 \%$ dos integrantes da amostra possuem pelo menos curso superior incompleto.

Inicialmente, a análise fatorial exploratória foi elaborada com as cinco variáveis que compõem os dois constructos. Os resultados obtidos mostram um KMO de 0.634 e o teste de esfericidade significante $(\mathrm{p}<0.01)$. Na Tabela 1, a matriz anti-imagem mostra que os valores de MSA (diagonal principal) são altos e não inferiores aos demais valores fora da diagonal, mais uma vez, atendendo aos requisitos para a aplicação da técnica (FÁVERO et al., 2009). 
Tabela 1 - Matriz anti-imagem

\begin{tabular}{|c|c|c|c|c|c|c|}
\hline & 1 & 2 & 3 & 4 & 5 & Comunalidades \\
\hline 1. Tempo médio gasto na Internet & $0,537 a$ & & & & & 0,763 \\
\hline $\begin{array}{l}\text { 2. Tempo médio gasto em mídias } \\
\text { sociais }\end{array}$ & $-0,517$ & $0,526 \mathrm{a}$ & & & & 0,764 \\
\hline $\begin{array}{l}\text { 3. Opinião positiva na sua mídia social } \\
\text { e intenção de compra }\end{array}$ & $-0,025$ & $-0,042$ & $0,651 \mathrm{a}$ & & & 0,742 \\
\hline $\begin{array}{l}\text { 4. Opinião negativa na sua mídia } \\
\text { social e intenção de compra }\end{array}$ & 0,183 & $-0,009$ & $-0,489$ & $0,665 a$ & & 0,713 \\
\hline $\begin{array}{l}\text { 5. Opinião do produto/marca/empre- } \\
\text { sa de dentro da sua mídia social }\end{array}$ & $-0,036$ & 0,085 & $-0,300$ & $-0,233$ & $0,758 \mathrm{a}$ & 0,602 \\
\hline
\end{tabular}

Fonte: Os autores (2014)

0 método de extração dos fatores usados foi análise de componentes principais, com rotação Varimax, resultando em um fator (eigenvalue maior que um) cuja porcentagem de explicação da variância é de $71,68 \%$, em que o fator 1 explica 40,83\%, e o fator 2, 30,85\%. Isso mostra que os dois fatores retidos têm pesos próximos para explicar a variância. A Tabela 2 apresenta as cargas fatoriais dos fatores retidos.

Tabela 2 - Fatores retidos

Componentes

\begin{tabular}{lcc}
\hline & $\mathbf{1}$ & $\mathbf{2}$ \\
\hline 1. Tempo médio gasto na Internet & $-0,112$ & $\mathbf{0 , 8 6 6}$ \\
\hline 2. Tempo médio gasto em mídias sociais & $-0,270$ & $\mathbf{0 , 8 7 4}$ \\
\hline 3. Opinião positiva na sua mídia social e intenção de compra & $\mathbf{0 , 8 6 1}$ & 0,010 \\
\hline 4. Opinião negativa na sua mídia social e intenção de compra & $\mathbf{0 , 8 2 9}$ & $-0,159$ \\
\hline 5. Opinião do produto/marca/empresa de dentro da sua mídia social & $\mathbf{0 , 7 7 4}$ & 0,055 \\
\hline
\end{tabular}

Fonte: Os autores (2014)

Com base na análise fatorial, a regressão foi feita, de modo a verificar a associação entre as variáveis e, assim, responder ao problema de pesquisa - relação entre a decisão de compra e a intensidade da exposição à internet e mídias sociais. A Tabela 3 apresenta as correlações das variáveis em questão. As variáveis independentes não têm correlação significativa, o que elimina a possibilidade de multicolinearidade, exceto a correlação entre credibilidade e decisão. Portanto, no modelo de regressão apenas serão usadas as duas variáveis em conjunto caso não apresentem VIF superior a 5 (HAIR et al., 2009).

\begin{tabular}{cccc}
\multicolumn{4}{c}{ Tabela 3- Correlaçōes das variáveis } \\
\hline & $\mathbf{1}$ & $\mathbf{2}$ & $\mathbf{3}$ \\
\hline 1. Importância & 1 & & \\
2. Intensidade de acesso & $-0,135$ & 1 & \\
3. Decisão de compra & $-0,199^{* *}$ & $0,173^{*}$ & 1 \\
\hline${ }^{*} \mathrm{p}<0,05$ & & & \\
${ }^{* *} \mathrm{p}<0,01$ & & &
\end{tabular}

Fonte: Os autores (2014)

0 modelo de regressão é apresentado na Tabela 4. A multicolinearidade entre as variáveis foi medida pelo teste VIF. Os resultados do teste apresentam valores inferiores a 5 para todos os constructos; portanto, não há evidências de ocorrência de multicolinearidade (HAIR et al., 2009). 0 modelo 1 apresenta apenas as variáveis independentes e o modelo 2 apenas as variáveis de controle. 0 modelo 3 é entendido como o modelo completo e analisa as variáveis independentes e as variáveis controladas de modo conjunto. 


\begin{tabular}{|c|c|c|c|c|}
\hline & \multicolumn{3}{|c|}{ Decisão de compra } & \multirow[t]{2}{*}{ VIF } \\
\hline & Modelo 1 & Modelo 2 & Modelo 3 & \\
\hline Constante & 3,437 & & 3,530 & \\
\hline Intensidade de acesso & $-0,170^{* *}$ & $-\mathrm{x}-$ & $0,159 * *$ & 1,044 \\
\hline Importância & $0,145^{*}$ & $-\mathrm{x}-$ & $-0,169^{* *}$ & 1,051 \\
\hline Faixa etâria & $-\mathrm{x}-$ & 0,033 & $-0,155$ & 1,024 \\
\hline Gênero & $-\mathrm{x}-$ & $-0,130$ & $-0,043$ & 1,036 \\
\hline $\mathrm{F}$ & $6,628^{*}$ & 0,562 & $3,738^{* *}$ & \\
\hline R2 ajustado & 0,052 & $-0,004$ & 0,051 & \\
\hline
\end{tabular}

$* \mathrm{p}<0.05 * * \mathrm{p}<0.01$

Os resultados mostram que o modelo 2 sem as variáveis independentes não apresenta significância estatística $(F>0.05)$. Acrescentando a variável independente, observa-se que no modelo 3 com $R^{2}$ de $5,1 \%$ de ajuste da curva de regressão. Interpretando o modelo 3, pode-se dizer que, quanto maior a intensidade de acesso à internet, maior é a propensão à decisão favorável pela compra, demonstrando associação positiva entre as variáveis. A mesma influência positiva pode ser verificada relativamente ao outro constructo, na medida em que, quanto maior a importância das informações disponíveis na internet, maior a disposição do cliente à compra. Conforme esperado, existe uma associação entre a decisão de compra do cliente e a variável intensidade de acesso à internet. Da mesma forma, identificamos associação significativa entre a decisão de compra e a importância das informações disponíveis na internet.

Dessa forma, os resultados suportam a H1, ou seja, existe uma associação no que diz respeito à decisão de compra do cliente e a intensidade de acesso à internet $(\mathrm{p}<0,01)$. Conforme esperado, quanto maior o tempo e a exposição a conteúdos on-line, maior a influência da exposição no ambiente on-line na decisão de compra dos usuários. Isso pois os internautas têm a possibilidade de avaliar diversas facetas acerca do produto de interesse no período pré-compra (BLACKWELL; MINIARD; ENGEL, 2001). Como a informação na internet pode ser originada de diversas fontes (MANTOVANI; SANTOS JUNIOR, 2013), muitas vezes desestruturadas, cabe ao usuário pesquisar aquela que lhe é útil, processo que leva tempo.

A importância atribuída às informações coletadas on-line apresenta-se como fator relevante na decisão de compra do consumidor, o que suporta a hipótese H2. Atualmente, a busca de informações em mídias sociais é recorrente, e pesquisas indicam que as pessoas buscam mais informações na internet do que em livros, jornais ou em conversas face a face (FLANAGIN, 2000). 0 acesso a informações, sejam provenientes da empresa ou de outros consumidores, permite a redução de riscos como prevenção de falhas no produto, pois estes estariam recomendados por outros consumidores em situação equivalente (GARBARINO; STRAHILEVITZ, 2004). Entretanto, como o meio virtual é livre e democrático, qualquer indivíduo ou empresa pode alimentar a rede com informações e conteúdos, verossímeis ou não (MANTOVANI; SANTOS JUNIOR, 2013). Nesse sentido, o usuário possui papel ativo na verificação do conteúdo, pois ele avalia a confiabilidade das informações acessadas na rede (FLANAGIN, 2000; TOMAÉL et al., 2001).

Todavia, para surpresa, as variáveis de controle gênero e idade do entrevistado não apresentaram significância estatística. Uma possível explicação sobre a relevância da variável idade pode ser a concentração dos respondentes na faixa etária de 18 a 29 anos identificada na amostra. Como 61\% da amostra faz parte dessa faixa etária, a distribuição não equitativa dos respondentes pode haver influenciado o resultado. Sobre o gênero, a amostra apresenta distribuição equitativa. Os resultados da análise indicam que a variável sexo não influenciou na decisão de compra dos respondentes. Tal resultado contradiz o esperado, pois que contraria achados de outras pesquisas realizadas a respeito do efeito gênero na internet (AKHTER, 2003; GARBARINO; STRAHILEVITZ, 2004). Abreu et al. (2010), por exemplo, em estudo sobre a comunicação na internet direcionada a gêneros distintos, verificam que há alguma diferença na percepção entre indivíduos de diferentes sexos. 0 presente estudo, por sua vez, não analisou comunicações de marketing direcionadas especificamente a um gênero ou outro, mas buscou abranger as informações em todos os seus formatos e fontes, sejam estruturada ou não. 


\section{CONCLUSÕES}

Em pouco mais de uma década, a comunicação entre empresas e pessoas passou por profunda transformação. A comunicação passa do antigo modelo unidirecional para novo formato multidirecional, em que indivíduos, grupos de interesse e empresas começam a interagir e a se comunicar livremente (TERRA, 2011). Nesse contexto, o artigo investiga a influência das informações obtidas nas mídias sociais nas decisões de compra dos internautas. Especificamente, o estudo relaciona a decisão de compra à intensidade da exposição à internet e mídias sociais (entendido como tempo on-line). Ainda, o estudo avalia se as decisões de compra dos internautas podem ser associadas à importância atribuída às informações.

0 presente estudo logrou associar a intensidade de acesso à rede e a credibilidade dos comentários, conteúdos e posts com decisões de compra de usuários de mídias sociais, cumprindo com seus objetivos de pesquisa. Ambas as hipóteses 1 e 2 foram confirmadas, indicando que a intensidade de acesso às mídias sociais (tempo on-line) influencia na decisão de compra desses consumidores. Além disso, identificou-se relação positiva entre a credibilidade e a importância das opiniões dadas na internet nas decisões de compra dos consumidores. Dessa maneira, foi possível atender aos objetivos da pesquisa.

Ao se verificar, de forma exploratória, que conteúdos na internet influenciam nas decisões de compra dos consumidores, o estudo reforça o papel e a responsabilidade das empresas na gestão desse canal de comunicação. 0 resultado deste artigo, associado ao estudo de Nassar (2013), indica que há ainda ampla possibilidade de intensificação do envolvimento dos gestores de comunicação corporativa das empresas com os conteúdos associados às suas marcas e produtos no ambiente virtual.

Uma questão que pode ter influenciado nas respostas coletadas é a ocorrência do chamado viés de desejabilidade social (PINTO et al., 2013). Esse viés resulta de respostas que não são baseadas naquilo que o respondente crê realmente, mas no que acredita ser socialmente apropriado. Sendo assim, é facilmente compreensível que, sobre questões trabalhadas no estudo, algum viés de desejabilidade social tenha impactado nas respostas.

Como oportunidade de estudos futuros, o tema aqui abordado aponta em múltiplas direções. Uma oportunidade seria identificar quais os critérios de credibilidade adotados pelos usuários de mídias virtuais para a validação das informações coletadas na rede. Nessa direção, destacamos a pesquisa de Tomaél et al. (2001); porém, o tema ainda pode ser desenvolvido. Outra direção de pesquisa, no contexto em foco, é a análise das estratégias empreendidas pelas empresas no ambiente virtual. Seriam estas de natureza reativa, relacionadas à contenção de reclamações (CLARO; SOUZA; MENA, 2013), ou de modo ativo, visando aproximação da empresa com seus públicos de interesse, empreendendo ações de co-criação ou de experimentação ou teste de produto? 0 uso de plataformas digitais para testes e feedbacks de produtos apresenta-se como oportunidade de novas pesquisas a fim de avançar no entendimento das particularidades desse novo modelo configurado em rede.

\section{ASSOCIATION BETWEEN INTENSITY OF SOCIAL MEDIA USAGE, CREDIBILITY AND PURCHASE DECISION}

\section{ABSTRACT}

The objective of this research is to analyse the relationship between the use of social media, the credibility of online information with the purchasing decisions of consumers. The research was carried out based on theoretical references to social networks, social media and on-line shopping behaviour. Data was collected via electronic survey and analyzed using factor analysis and multiple linear regression. The results indicate the association between the customers' decision to purchase and the intensity of their Internet access. Customers'decision to buy and the importance of information viewed on the internet are also related. The longer the exposure to online content, the greater the influence on users'shopping decisions. Unlike previous studies, no significant association between the variables of gender and age of the respondents to the survey was observed in what concerns their shopping decisions.

Keywords: Social media. Purchase decision. Internet. Social networks. Shopping behavior. 


\section{REFERÊNCIAS}

ABREU, N. R. et al. Estudo da percepção de gêneros sobre a comunicação em sites na internet. Revista de Administração e Inovação, São Paulo, v. 7, n. 2, p. 60-79, 2010.

AKHTER, S. H. Digital divide and purchase intention: Why demographic psychology matters. Journal of Economic Psychology, Bolton, v. 24, n. 3, p. 321-327, 2003. doi: http://dx.doi.org/10.1016/S01674870(02)00171-X.

ANDERSON, C. Free grátis: o futuro dos preços. Rio de Janeiro: Elsevier, 2009.

BEARDEN, W. O.; ETZEL, M. J. Reference group influence on product and brand purchase decisions. Journal of Consumer Research, Chicago, v. 9, n. 4, p. 183-194, 1982.

BLACKWELL, R. D.; MINIARD, P. W.; ENGEL, J. F. Consumer behavior. 9. ed. Mason: South- Western, 2001.

CAMPBELL, C. A ética romântica e o espírito do consumismo moderno. Rio de Janeiro: Rocco, 2001.

CARDOSO, R. Estratégia global leva em conta a cor local. Valor Setorial - São Paulo Comunicação Corporativa: conteúdo em novo formato, São Paulo, v. 11, n. 90, p. 34-40, 2013.

CARVALHO, J. Virais conquistam público com ações interativas. Valor Setorial - São Paulo Comunicação Corporativa: conteúdo em novo formato, São Paulo, v. 11, n. 90, p. 22-26, 2013.

CASTELLS, M. A Galáxia Internet: reflexões sobre a Internet, negócios e a sociedade. Rio de Janeiro: Zahar, 2003.

CERETTA, S. B.; FROEMMING, L. M. Geração Z: compreendendo os hábitos de consumo da geração emergente. RAUnP - Revista Eletrônica do Mestrado Profissional em Administração da Universidade Potiguar, Natal, v. 3, n. 2, p. 15-24, 2011.

CLARO, J. A. C. D. S.; SOUZA, J. R.; MENA, R. J. F. Estudo comparativo Brasil-Portugal sobre o uso de redes sociais na Internet por jovens como instrumento de reclamação junto de empresas. Revista de Administração da Unimep, Piracicaba, v. 1, n. 3, p. 142-172, 2013.

COOPER, D.; SCHINDLER, P. Métodos de Pesquisa em Administração. Porto Alegre: Bookman, 2006.

CRUZ, B. P. A. et al. Influência de brasileiros famosos no boicote de consumidores que usam redes sociais virtuais. Revista de Negócios, Blumenau, v. 17, n. 2, p. 91-110, 2012.

ELLISON, N. B.; STEINFIELD, C.; LAMPE, C. The Benefits of Facebook "Friends:" Social Capital and College Students' Use of Online Social Network Sites. Journal of Computer-Mediated Communication, Washington, v. 12, n. 4, p. 1143-1168, 2007. doi: 10.1111/j.1083-6101.2007.00367.x.

FÁVERO, L. P. L. et al. Análise de Dados: Modelagem Multivariada para Tomada de Decisões. Rio de Janeiro: Campus Elsevier, 2009.

FERNANDES, L. D. O.; RAMOS, A. S. M. Intenção de compra online: aplicação de um modelo adaptado de aceitação da tecnologia para o comércio eletrônico. Revista Eletrônica de Sistemas de Informação, Curitiba, v. 11, n. 1, p. 1-22, 2012.

FLANAGIN, A. J. Perceptions of Internet information credibility. Journalism \& Mass Communication Quarterly, Chapel Hill, v. 77, n. 3, p. 515-540, 2000.

GARBARINO, E.; STRAHILEVITZ, M. Gender differences in the perceived risk of buying online and the effects of receiving a site recommendation. Journal of Business Research, Chestnut Hill, v. 57, n. 7, p. 768775, 2004. doi: http://dx.doi.org/10.1016/S0148-2963(02)00363-6. 
GARTON, L.; HAYTHORNTHWAITE, C.; WELLMAN, B. Studying Online Social Networks. Journal of Computer-Mediated Communication, Washington, v. 3, n. 1, 1997. doi: 10.1111/j.1083-6101.1997. tb00062.x.

HAIR, J. F. et al. Análise Multivariada de Dados. Porto Alegre: Bookman, 2009. v. 6.

JOINES, J. L.; SCHERER, C. W.; SCHEUFELE, D. A. Exploring motivations for consumer Web use and their implications for e-commerce. Journal of Consumer Marketing, South Florida, v. 20 n. 2, p. 90-108, 2003.

KOTLER, P.; KARTAJAYA, H.; SETIAWAN, I. Marketing 3.0: as forças que estão definindo o novo marketing centrado no ser humano. Rio de Janeiro: Elsevier, 2010.

MALHORTRA, N. K. Pesquisa de Marketing: uma orientação aplicada. 3. ed. Porto Alegre: Bookman, 2001.

MANTOVANI, D. M. N.; SANTOS JUNIOR, D. L. D. Relações nas redes sociais: geração de conteúdo, criação de networking e projeção das relações virtuais nas comunidades do ORKUT. Revista de Administração e Inovação, São Paulo, v. 10, n. 3, p. 37-64, 2013.

MARTELETO, R. M. Análise de redes sociais: aplicação nos estudos de transferência da informação. Ciência da Informação, Brasília, v. 30, n. 1, p. 71-81, 2001.

MENEZES, L. Uma questão de ética ou disciplina? Valor Setorial - São Paulo. Comunicação Corporativa: conteúdo em novo formato, São Paulo, v. 11, n. 90, p. 88-90, 2013.

MOTTA, M. Geografia dos domínios de internet no Brasil. Revista Brasileira de Inovação, Campinas, v. 12, n. 2, p. 311-344, 2013.

NAGAKAWA, S. S. Y.; GOUVÊA, M. A.; OLIVEIRA, B. A lealdade ao canal de comercialização e ao fornecedor nas compras em ambientes físico e online. Revista de Administração e Inovação, São Paulo, v. 10, n. 4, p. 6-37, 2013.

NASSAR, P. Perfil do profissional de comunicação organizacional no Brasil. Rio de Janeiro: ABERJE, 2013.

NIELSEN GLOBAL SURVEY OF TRUST IN ADVERTISING. Under the influence: consumer trust in advertising. [2013]. Disponível em: <http://www.nielsen.com/us/en/newswire/2013/under-theinfluence-consumer-trust-in-advertising.html>. Acesso em: 16 jun. 2014.

PATRICK, K.; DOTSIKA, F. Knowledge sharing: developing from within. Learning Organization, Chapman, v. 14 , n. 5 , p. $395-406,2007$.

PINTO, M. et al. Analisando as Motivações para Aceitação e Adoção de Redes Sociais Virtuais. Revista Gestão \& Tecnologia, Pedro Leopoldo, v. 13, n. 2, p. 45-71, 2013.

RECUERO, R. Redes sociais na internet. Porto Alegre: Sulina, 2009.

RIDINGS, C. M.; GEFEN, D.; ARINZE, B. Some antecedents and effects of trust in virtual communities. The Journal of Strategic Information Systems, Waltham, v. 11, n. 3-4, p. 271-295, 2002. doi: http://dx.doi. org/10.1016/S0963-8687(02)00021-5.

ROKEACH, M. The nature of human values. New York: Free press, 1973.

SMOLA, K. W.; SUTTON, C. D. Generational differences: Revisiting generational work values for the new Millennium. Journal of Organizational Behavior, Malden, v. 23, n. 4, p. 363-382, 2002.

SOLOMON, M. R. Comportamento do consumidor: comprando, possuindo e sendo. 5. ed. Porto Alegre: Bookman, 2002. 
TERRA, C. F. 0 que as organizações precisam fazer para serem bem vistas nas mídias sociais sob a ótica da comunicação organizacional e das relações públicas. In: Congresso Científico de Comunicação Organizacional e Relações Públicas, 5., 2001, São Paulo. Anais... São Paulo: ABRACORP, 2011. p. 1-15.

TOMAÉL, M. I. et al. Avaliação de fontes de informação na internet: critérios de qualidade. Informação \& Sociedade: Estudos, João Pessoa, v. 11, n. 2, p. 1-14, 2001.

TOTOLI, F; ROSSI, G. B. Mídias sociais promovendo lealdade: um estudo empírico sobre o Twitter. Espacios, Caracas, v. 33, p. 14-14, 2012.

VAN DER HEIJDEN, H.; VERHAGEN, T.; CREEMERS, M. Understanding online purchase intentions: contributions from technology and trust perspectives. European Journal of Information Systems, Birmingham, v. 12, n. 1, p. 41-48, 2003.

VAN RULER, B. The communication grid: an introduction of a model of four communication strategies. Public Relations Review, Maryland, v. 30, n. 2, p. 123-143, 2004. doi: http://dx.doi.org/10.1016/j. pubrev.2004.01.002.

VAZ, C. A. Os oito Ps do marketing digital: o seu guia estratégico de marketing digital. São Paulo: Novatech, 2012.

WOERKUM, C. V.; AARTS, N. Staying connected: The communication between organizations and their environment. Corporate Communications: An International Journal, Amsterdam, v. 13, n. 22, p. 197-211, 2008.

WONG, N.; RINDFLEISCH, A.; BURROUGHS, J. E. Do reverse-worded items confound measures in crosscultural consumer research? The case of the material values scale. Journal of Consumer Research, Chigaco, v. 30, n. 1, p. 72-91, 2003.

WRIGHT, B., \& SCHWAGER, P. H. Online Survey Research: Can Response Factors Be Improved? Journal of Internet Commerce, Philadelphia, v. 7, n. 2, p. 253-269, 2008. doi:10.1080/15332860802067730. 